\title{
Качественные и количественные характеристики трансляции культурной информации
}

\author{
Сидоренко В.А. \\ Луганский государственный медицинский университет имени Святителя Луки, \\ Луганская Народная Республика, 91045, г. Луганск, кв. 50 лет Обороны Луганска, 1г \\ E-mail: philosophy.lsmu@mail.ru
}

\begin{abstract}
Аннотация. Трансляция культурной информации является основополагающим процессом в системе социальной адаптации индивида. Получение из культуросферы структурированной, отфильтрованной и готовой к употреблению информации в отношении стоящих перед человеком задач значительно снижает нагрузку на его когнитивную систему, что особенно актуально в свете стремительно увеличивающихся объемов информации в современном мире. Автором рассмотрены качественные (объективность, достоверность, полнота, полезность, ясность, доступность, устойчивость) и количественные (объем, дискретность, скорость передачи данных, пропорциональное соотношение направлений коммуникации, количество иерархических и параллельных системных связей) параметры культурной трансляции. Также проанализированы различные методологии изучения процессов культурного обмена, предлагаемые смежными с философией областями знания, такими как психология, культурология, лингвистика, этнография и общая теория информации.
\end{abstract}

Ключевые слова: информационный взаимообмен, культурная адаптация, эмпирические медиаторы, классификация коммуникативных схем, интериоризация и формализация культурного знания.

Для цитирования: Сидоренко В.А. 2020. Качественные и количественные характеристики трансляции культурной информации. NOMOTHETIKA: Философия. Социология. Право. 45 (4): 696-703. DOI 10.18413/2712-746X-2020-45-4-696-703

\section{Qualitative and quantitative features of the cultural information translation}

\author{
Vladimir A. Sidorenko \\ State Establishment of Lugansk People's Republic \\ Saint Luka Lugansk State Medical University, \\ 1g 50 Let Oborony Luganska B1., Lugansk, 91045, Lugansk People’s Republic
}

\begin{abstract}
Translation of cultural information is a fundamental process in the system of individual's social adaptation. Obtaining of structured, filtered and ready-to-use information from the cultural sphere significantly reduces the load on the person's cognitive system in relation to the tasks faced, which is especially important due to rapidly increasing volumes of information in the modern world. The paper discusses qualitative (objectivity, reliability, completeness, usefulness, clarity, accessibility, stability) and quantitative (volume, discreteness, data transfer rate, proportional relationship of communication directions, number of hierarchical and parallel system connections) cultural translation parameters. It also analyzes various methodologies for studying the processes of cultural exchange offered by the fields of knowledge adjacent to philosophy, such as psychology, cultural studies, linguistics, ethnography, and the general theory of information.
\end{abstract}

Key words: informational interchange, cultural adaptation, empirical mediators, classification of communicative schemes, internalization and formalization of cultural knowledge. 
For citation: Sidorenko V.A. 2020. Qualitative and quantitative features of the cultural information translation. NOMOTHETIKA: Philosophy. Sociology. Law series. 45 (4): 696-703 (in Russian). DOI 10.18413/2712-746X-2020-45-4-696-703

Процесс трансляции культурного знания является основополагающим для формирования общего вектора развития цивилизации как в локальном, так и в общечеловеческом масштабе. Взаимообмен культурным знанием между индивидом и глобальным информационным массивом носит двусторонний характер - он может быть направлен как от индивида к культуросфере, так и наоборот. В первом случае коммуникация носит более креативный характер, пополняя массив накопленных человечеством ответов на встающие перед ним вызовы, в то время как во втором случае коммуникативный процесс становится более адаптивным, направленным на приведение индивидуального мировоззрения субъекта в соответствие с общекультурным направлением развития. Оба направления трансляции характеризуются как сходными, так и различными качественными и количественными параметрами, рассмотрению которых посвящена настоящая статья.

Историко-философские аспекты коммуникативной атрибуции культуры отражены в антропологических концепциях И.Ю. Алексеевой и Е.А. Никитиной [2015], T.В. Андриановой [2014], И.Н. Валиева [2017], Э. Канделя [2016], Д. Ланди [2016], М. Маклюэна [2013], Г. Маркузе [2013], Н.В. Морошкиной и В. А. Гершкович [Морошкина, 2013; Морошкина, Гершкович, 2014], Т.В. Науменко [2013, 2015], Т.С. Паниотовой [2014], Г. Пауля [2013]. Практические аспекты информационной трансляции нашли отражение в исследованиях А. Бека, Й. Ш. Давыдова, М.С. Кагана, А. Г. Киселева, С. Корбриджа, С. А. Матяша, Б. Шора.

Основными параметрами транслируемой информации являются следующие [Киселев, 2011, с. 27]:

1) объективность - независимость информации от воли субъекта;

2) достоверность - обоснованность и доказанность транслируемых данных;

3) полнота - достаточность информации для понимания поставленной задачи и принятия правильного решения;

4) полезность - обеспечение нахождение решения именно для поставленной задачи;

5) ясность - кодирование информации в символах, максимально доступных пониманию реципиента.

Информация, максимально реализующая вышеупомянутые качественные показатели при минимальном объеме, получила название «идеальной» [Давыдов, 2004, с. 166]. В зависимости от целей и содержания коммуникативного акта предпочтение может отдаваться либо качеству, либо объему данных, приближая их к идеальным параметрам. Количественные показатели задействуют в основном элементы когнитивной системы субъекта, отвечающие за хранение информации, в то время как качественные воздействуют на систему ее обработки. На стыке качественных и количественных параметров лежит процесс кодирования-декодирования, позволяющий сбалансировать их в нужной пропорции. При необходимости уменьшить объем данные сжимаются и кодируются сильнее, что неизбежно приводит к потере качества, и наоборот - высокое качество трансляции требует большего объема и большей нагрузки на ментальные структуры субъекта.

В ряду качественных характеристик транслируемой информации следует отметить такие ее свойства, как достаточность, актуальность, доступность и устойчивость [Матяш, 2015 , с. 30]. Достаточность данных представляет собой их оптимальный объем, необходимый для решения конкретной ситуативной задачи. При этом негативный эффект будут иметь как нехватка транслируемой информации, поскольку задача не будет решена в полном объеме, так и ее избыток, перегружающий когнитивную систему субъекта и снижаю- 
щий эффективность ее обработки. Актуальность информации состоит в точном соответствии поступающих данных поставленной задаче с целью избежать вышеупомянутых отклонений - ее недостаточности или избыточности. Доступность культуросферы в современном информатизированном обществе непрерывно возрастает. Все чаще при возникновении проблемы человек вместо поиска собственного решения ищет готовый ответ в культуросфере, понимая, что среди миллиардов представителей нынешнего поколения и еще большего количества представителей предыдущих кто-нибудь когда-нибудь, скорее всего, уже сталкивался с подобной проблемой и оставил информацию об этом в культуросфере. Отсюда вытекает такое свойство культурной информации, как устойчивость. Под устойчивостью следует понимать способность данных сохраняться во времени, не теряя актуальности и эффективности. Устойчивость часто трактуют как консервативность [Corbridge, 2000, с. 307], однако это не соответствует действительности. Наоборот, устойчивая информация активно видоизменяется, адаптируясь к новым запросам, но при этом сохраняет преемственность по отношению к предшествующим формам, что обеспечивает цельность и хронологическое постоянство культуросферы.

Рассмотрев качественные характеристики транслируемой информации как объекта взаимоотношений индивид - культуросфера, необходимо обратить внимание и на свойства субъекта этих отношений. Среди характеристик субъекта коммуникативного процесса можно выделить следующие:

- унификацию - каждый субъект коммуникативных процессов так или иначе принимает универсальные стандарты, содержащиеся в культуре. Таким образом, происходит унификация субъектов культуры, что за счет увеличения репрезентативности в свою очередь усиливает культурные доминанты культуросферы;

- эмуляцию - при получении культуросферного знания в сознании субъекта формируется сектор, не совпадающий с уже существующими мировоззренческими установками. Данный сектор является эмулятором фрагмента культуросферы, который впоследствии, в процессе интериоризации, будет включен полностью либо частично в индивидуальную систему субъекта;

- локализацияю - воспринятые в результате коммуникации идеи подвергаются корректировке с целью согласования со спецификой локальной культуры. Даже в случае абсолютной идентичности задачи, стоящей перед субъектом, и задачи, решение которой уже содержится в культуросфере, входящие данные проходят через систему социокультурных фильтров, адаптирующих теоретическую информацию к конкретной ситуации реализации;

- взаимопроникновение - трансляция культурного опыта двустороння: видоизмененное в процессе локализации знание возвращается в культуросферу, где обрабатывается путем сравнения с ранее существовавшим. Таким образом, не только культуросфера проникает в сознание субъекта, но и его индивидуальное знание воздействует на глобальную систему информации. Такое взаимопроникновение является движущей силой развития обеих участвующих в коммуникации сторон;

- конкуренцию - процессы как получения, так и поставки культурной информации подчиняются законам конкуренции: каждый субъект стремится к получению более качественной информации по сравнению с другими субъектами, что позволит ему решать стоящие перед ним задачи с более высокой эффективностью; также субъект заинтересован в поставке максимально качественной информации в культуросферу, поскольку в этом случае именно его идеологические установки примут характер доминирующих в культуpe, что позволит субъекту экономить его собственные ментальные ресурсы за счет отсутствия необходимости интериоризации чужой идеологии и даст возможность использовать высвобожденные ресурсы для решения новых задач. Конкурентное преимущество в таком случае усиливается по принципу снежного кома, но стоит потерять это преимущество - и 
маховик конкуренции закрутится в обратную сторону: низкое качество экспортируемой в культуросферу информации влечет за собой снижение ее рейтинговости и объемов, ресурсы приходится затрачивать на локализацию и интериоризацию чужих идеологем вплоть до полного атрофирования собственной способности к творческому решению задач. Конкуренция субъектов культуросферной интеракции особенно важна в условиях современного потребительского общества, поскольку стимулирует не только иждивенческое получение готовых решений, но и поставку своих собственных идей.

Большая конкуренция в сфере поставки информации в культуросферу обусловлена все возрастающей скоростью обмена данными. Успешность субъекта данного процесса включает в себя два аспекта: быстрое и эффективное распространение выработанной информации и собственный доступ к результатам других субъектов. Следствием двойственной природы информационного обмена стал, например, тот факт, что Нобелевская премия в большинстве областей в наши дни вручается не одному ученому, а целому ряду исследователей, пришедших к одинаковому решению одной и той же задачи. Это говорит о том, что скорость обмена информацией настолько высока, что не представляется возможным определить первенство того или иного автора в пополнении культуросферы своим решением. Современное человечество все чаще задумывается о необходимости регулирования процесса культурного обмена. Поскольку его практическая реализация обеспечивается, в первую очередь, информационными технологиями, в 2000 году была принята Окинавская хартия, в которой были закреплены такие важнейшие принципы формирования глобального информационного общества, как обеспечение каждому индивиду возможности доступа к любой информации и общения с любым членом общества, народа, нации. Скоординированные действия ведущих стран мира по обеспечению равноправия в области доступа к культуросфере ведут к её еще более активному пополнению вследствие роста количества субъектов информационного обмена.

Качественные характеристики транслируемой информации дополняются количественными. Весь объем воспринимаемых данных можно разделить на неравные части в зависимости от эмпирического медиатора, задействованного в процессе культурной коммуникации. Основными формами передачи информации являются зрительная, звуковая и, значительно реже, тактильная. В зрительной форме воспринимается подавляющее большинство данных, порядка 80-90 \% [Каган, 2001, с. 135], причем относящихся не только к образно-символической сфере (символы письменной речи, художественные образы и т.п.), но и к поведенческой, морально-этической и другим областям человеческой экзистенции, в которых перед индивидом встают требующие решения задачи. Например, необходимая модель поведения может восприниматься и фиксироваться как цельный образ, применяемый по мере необходимости. В этом случае весь образ выступает в роли недискретной единицы культурной информации, что упрощает оперирование им. Схожими свойствами обладает и звуковая форма передачи, с той лишь разницей, что транслируемый объем данных является на порядок меньшим. К тому же зрительная и звуковая формы зачастую дополняют друг друга в рамках единого образа, усиливая таким образом его комплексность. Тактильная форма передачи информации в процессе культурной коммуникации используется редко, например, людьми с ограниченными физическими возможностями, которые по той или иной причине лишены возможности воспринимать информацию традиционными для большинства людей способами.

В условиях ежедневной коммуникативной активности субъекта особую важность приобретает такая функция, как повышение эффективности восприятия информации. Другими словами, то, что ложится в рамки уже существующей ментальной структуры и не противоречит ей, воспринимается легче, чем то, что требует отдельного осмысления и классификации, поскольку задействует меньшее количество мыслительных ресурсов. Также менее ресурсоемким становится процесс обработки информации, занимающей определенную позицию в информационной структуре, по сравнению с выходящей за ее 
пределы. При этом чем более разветвленной является информационная структура, чем больше в ней внутренних связей, тем меньше усилий будет тратиться на актуализацию единицы информации и ее использование в коммуникативном процессе.

Большое количество внутренних иерархических и параллельных связей увеличивает степень точности и корректности задействованной в коммуникации информации. Так, например, услышав новое слово (увидев новый объект, придя к новому умозаключению и т. д.), человек встраивает приобретенную единицу в уже существующую информационную систему. Если незнакомое доселе слово получило при этом связи с другими информационными единицами (синонимичными, антонимичными, похожими этимологически, морфологически и т. д.), субъект получает возможность использовать данную единицу более точно. При отсутствии информационных связей полученные данные часто переводятся в категорию пассивных, малозадействованных в мыслительных процессах, активизируясь постепенно в процессе занятия своей ниши в информационной структуре.

Возможен и обратный механизм: информационный фрагмент с малым количеством «ссылок» (англ. link, связи компонентов информационной структуры между собой, а также интерсхемные связи) попадает в информационную среду, где деактуализируется, становясь пассивным. Накапливая ссылки (особенно в случае активной информационной среды: чем активнее среда, тем более многочисленными, устойчивыми и надежными являются ссылки), информационная структура или ее компонент актуализируются, повышая свой когнитивный рейтинг. При этом набор связей формируется как в рамках индивидуальной информационной системы субъекта, так и в надындивидуальном общекультурном информационном массиве.

Отклонения в информационной структуре, ее неадекватность окружающей действительности, в том числе и культурной, могут реализовываться в различных формах психических расстройств, начиная с повышенной эмоциональной чувствительности, эмоциональной неустойчивости, недостаточной уверенности в себе и заканчивая полноценными психическими заболеваниями. Данные отклонения получили название «информационной уязвимости» [Бек и др., 2003, с. 7].

В философской литературе, посвященной разработке теории коммуникации нередко возникает некоторая путаница, связанная с недостаточной разработанностью терминологической базы. Чаще всего в качестве ее информационных компонентов фигурируют термины «культурная модель», «коммуникативная модель», «скрипт», «коммуникативная схема». Прояснить данную ситуацию попытался Б. Шор. Шор выделяет следующие информационные категории: индивидуальные ментальные модели (personal mental models), конвенциональные ментальные модели (conventional mental models), институциональные модели (instituted models) и фундаментальные схемы (foundational schemas) [Shore, 1996, p. 41-48].

При использовании такой классификации нивелируются противоречия между сторонниками универсальных коммуникативных схем, присущих любому представителю человечества, и защитниками вышеупомянутой теории о наличии дифференцирующих схем у представителей различных культурных групп, поскольку первые будут принадлежать к фундаментальным механизмам, а вторые - к институциональным или конвенциональным. Основной проблемой при таком подходе остается вопрос изменчивости фундаментальных структур: если фундаментально схемы неизменны, то их функциональное, институциональное или конвенциональное разнообразие лишается базисной основы. Фундаменталисты трактуют разнообразие как недостаток, неполноценность коммуникации, в то время как сторонники дифференцирующего характера информационных структур, возражая против обеспечения всех едиными моделями (к чему зачастую и сводят культурную коммуникацию), пытаются выявить каналы обмена информацией при сохранении идентичности группы. Сторонники универсальных структур относят антропологические различия к несущественным вариациям, лежащим скорее в области психологии, лингвистики, этно- 
графии и других более конкретных наук, в то время как объектом философской антропологии являются именно универсальные структуры.

Поэтому последствия междисциплинарности классификационных подходов являются двоякими: с позиций каждой из отраслей знания свойства коммуникативных механизмов рассмотрены достаточно объемно, однако комплексная классификация так и не была сформирована. К тому же каждая наука перетягивала типологию либо в сторону индивидуализма (психология, этнография), либо в сторону коллективизма (лингвистика, теория познания). Философская антропология при анализе коммуникативных механизмов и процесса их формирования должна придерживаться определенного баланса: информационная система индивидуальна, но ее функционирование подчиняется общим законам детерминизма, телеологии, моделирования и другим, а также общекультурным доминантам, которые могут интериоризоваться или влиять на информационные структуры субъекта без усвоения.

\section{Заключение}

Вышеизложенное позволяет сделать ряд выводов:

1) качественные характеристики идеальной транслируемой информации обратно пропорциональны количественным;

2) в реальных условиях субъекты культурной коммуникации вынуждены искать баланс между повышением качества и снижением объема транслируемых данных;

3) оптимальный баланс характеристик достигается благодаря конкуренции как среди доноров, так и среди реципиентов культурной информации;

4) большинство культурных данных транслируется посредством медиаторов, вносящих собственные коррективы в качество и количество информации;

5) междисциплинарность данной области вносит некоторую сумятицу в методологию и терминологию исследований, обусловливая необходимость их систематизации и устранения дублирующих и взаимоисключающих элементов, что представляет собой одно из перспективных направлений работы в данной сфере.

\section{Список литературы}

1. Алексеева И. Ю., Никитина Е. А. 2015. Интеллект и технологии. М., Проспект, 96 с.

2. Андрианова Т. В. 2014. Глобальное мировоззрение. М., Директ-Медиа, 281 с.

3. Бек А., Раш А., Шо Б., Эмери Г. 2003. Когнитивная терапия депрессии. СПб., Питер, $304 \mathrm{c}$.

4. Валиев И.Н. 2017. Стереотипы социального взаимодействия. М., Прометей, 160 с.

5. Давыдов Й.Ш. 2004. Познание истины. Нью-Йорк, International Scientific Center, 424 с.

6. Каган М.С. 2001. Искусствознание и художественная критика. СПб., Петрополис, 527 с.

7. Кандель Э. 2016. Век самопознания: поиски бессознательного в искусстве и науке с начала XX века до наших дней. М., Издательство АСТ, 720 с.

8. Киселев А.Г. 2011. Теория и практика массовой информации. СПб., Питер, 400 с.

9. Ланди Д. 2016. Биоген. М., РИПОЛ КЛАССИК, 384 с.

10. Маклюэн М. 2013. Галактика Гутенберга: становление человека печатающего. М., Академический Проект, 496 с.

11. Маркузе Г. 2013. Эрос и цивилизация. Одномерный человек: Исследование идеологии развитого индустриального общества. М., АСТ, 527 с.

12. Матяш С.А. 2015. Корпоративные информационные системы. М.-Берлин, ДиректМедиа, $471 \mathrm{c}$.

13. Методологические проблемы социально-гуманитарных наук. 2013. Под ред. Т.В. Науменко. М., Научная библиотека,

14. Морошкина Н.В. 2013. Влияние конфликта имплицитных и эксплицитных знаний субъекта на результаты научения в задаче классификации. Экспериментальная психология, 3 : $62-73$. 
15. Морошкина Н. В., Гершкович В. А. 2014. Актуальные тенденции в исследовании имплицитного научения. Вестник Санкт-Петербургского государственного университета. Серия 16. Психология, педагогика, 4: 14-24.

16. Науменко Т.В. 2015. Массовая коммуникация как глобальный процесс. М., Научная библиотека, 398 с.

17. Паниотова Т.С. 2014. Культурная история Запада в контексте модернизации (XIX начало XXI в.). М.-Берлин, Директ-Медиа, 223 с.

18. Пауль Г. 2013. Принципы истории языка. Пер. с нем. под ред. А. А. Холодовича. М., Книга по требованию, $501 \mathrm{c.}$

19. Corbridge S. 2000. Development: Identities, Representations, Alternatives. London, Routledge, $329 \mathrm{p}$.

20. Shore B. 1996. Culture in Mind: Cognition, Culture and the Problem of Meaning. Oxford, Oxford University Press, 448 p.

\section{References}

1. Alekseeva I.Ju., Nikitina E.A. 2015. Intellekt i tehnologii: monografija [Intellect and technology: monograph]. Moscow, Publ. Prospekt, 96 p.

2. Andrianova T.V. 2014. Global'noe mirovozzrenie [Global outlook]. Moscow, Publ. DirektMedia, $281 \mathrm{p}$.

3. Beck A., Rush A., Shaw B., Emery G. 2003. Kognitivnaja terapija depressii [Cognitive therapy for depression]. Saint Petersburg, Publ. Piter, $304 \mathrm{p}$.

4. Valiev I.N. 2017. Stereotipy social'nogo vzaimodejstvija [Stereotypes of social interaction]. Moscow, Publ. Prometej, $60 \mathrm{p}$.

5. Davydov J. Sh. 2004. Poznanie istiny [Cognition of truth]. New-York, Publ. International Scientific Center, $424 \mathrm{p}$.

6. Kagan M.S. 2001. Iskusstvoznanie i hudozhestvennaja kritika [Art criticism]. Saint Petersburg, Publ. Petropolis, 527 p.

7. Kandel E. 2016. Vek samopoznanija: poiski bessoznatel'nogo v iskusstve i nauke s nachala XX veka do nashih dnej [Century of self-knowledge: the search for the unconscious in art and science from the beginning of the twentieth century to the present day]. Moscow, Publ. AST, $720 \mathrm{p} /$

8. Kiselev A. G. 2011. Teorija i praktika massovoj informacii [Theory and practice of the media]. Saint Petersburg, Publ. Piter, 400 p.

9. Landi D. 2016. Biogene. Moscow, Publ. RIPOL KLASSIK, 384 p. (in Russian)

10. McLuhan M. 2013. The Gutenberg Galaxy: The Becoming of the Person Printing. Moscow, Publ. Akademicheskij Proekt, 496 p. (in Russian)

11. Marcuse H. 2013. Eros and Civilization. One-Dimensional Man: A Study of the Ideology of a Developed Industrial Society. Moscow, Publ. AST, 527 p. (in Russian)

12. Matjash S.A. 2015. Korporativnye informacionnye sistemy [Corporate information systems]. Moscow-Berlin, Publ. Direkt-Media, 471 p.

13. Metodologicheskie problemy social'no-gumanitarnyh nauk. [Methodological problems of social and humanitarian Sciences]. 2013 Ed. T.V. Naumenko. Moscow, Publ. Nauchnaja biblioteka.

14. Moroshkina N.V. 2013. Influence of the conflict of implicit and explicit knowledge of the subject on the results of learning in the classification problem. Eksperimental'naja psihologija, 3: 62-73. (in Russian)

15. Moroshkina N. V., Gershkovich V. A. 2014. Actual trends in the study of implicit learning. Vestnik Sankt-Peterburgskogo gosudarstvennogo universiteta. Serija 16. Psihologija, pedagogika, 4: 1424. (in Russian)

16. Naumenko T. V. 2015. Massovaja kommunikacija kak global'nyj process [Mass communication as a global process]. Moscow, Publ. Nauchnaja biblioteka, 398. (in Russian)

17. Paniotova T. S. 2014. Kul'turnaja istorija Zapada v kontekste modernizacii (XIX - nachalo XXI v.): monografija [The cultural history of the West in the context of modernization (XIX - early XXI centuries): monograph]. Moscow-Berlin, Publ. Direkt-Media, 223. (in Russian)

18. Paul G. 2013. Principles of the History of Language. Moscow, Publ. Kniga po trebovaniju, $501 \mathrm{p}$. 
19. Corbridge S. 2000. Development: Identities, Representations, Alternatives. London, Routledge, $329 \mathrm{p}$.

20. Shore B. 1996. Culture in Mind: Cognition, Culture and the Problem of Meaning. Oxford, Oxford University Press, 448 p.

\section{ИНФОРМАЦИЯ ОБ АВТОРЕ}

\section{Сидоренко Владимир Александрович,} кандидат философских наук, доцент кафедры философии, правоведения, социальных и гуманитарных наук Луганского государственного медицинского университета имени Святителя Луки, Луганск, Луганская Народная Республика

\section{INFORMATION ABOUT THE AUTHOR}

Vladimir A. Sidorenko, Candidate of Philosophy, Associate Professor at the Department of Philosophy, Law, Social and Human Sciences, St. Luka State Medical University of Lugansk, Lugansk, Lugansk People's Republic 